\title{
Klotho Pathways, Myelination Disorders, Neurodegenerative Diseases, and Epigenetic Drugs
}

Walter H. Moos, ${ }^{1,2, *}$ Douglas V. Faller, ${ }^{3,4}$ Ioannis P. Glavas, ${ }^{5}$ David N. Harpp, ${ }^{6}$ Iphigenia Kanara, ${ }^{7}$ Anastasios N. Mavrakis, Julie Pernokas, ${ }^{9}$ Mark Pernokas, ${ }^{9}$ Carl A. Pinkert, ${ }^{10}$ Whitney R. Powers, ${ }^{11,12}$ Konstantina Sampani, ${ }^{13,14}$ Kosta Steliou, ${ }^{4,15}$ Demetrios G. Vavvas, ${ }^{13,16}$ Robert J. Zamboni, ${ }^{6}$ Krishna Kodukula, ${ }^{2, *}$ and Xiaohong Chen ${ }^{13,16, *}$

\begin{abstract}
In this review we outline a rationale for identifying neuroprotectants aimed at inducing endogenous Klotho activity and expression, which is epigenetic action, by definition. Such an approach should promote remyelination and/or stimulate myelin repair by acting on mitochondrial function, thereby heralding a life-saving path forward for patients suffering from neuroinflammatory diseases. Disorders of myelin in the nervous system damage the transmission of signals, resulting in loss of vision, motion, sensation, and other functions depending on the affected nerves, currently with no effective treatment. Klotho genes and their single-pass transmembrane Klotho proteins are powerful governors of the threads of life and death, true to the origin of their name, Fates, in Greek mythology. Among its many important functions, Klotho is an obligatory co-receptor that binds, activates, and/or potentiates critical fibroblast growth factor activity. Since the discovery of Klotho a little over two decades ago, it has become ever more apparent that when Klotho pathways go awry, oxidative stress and mitochondrial dysfunction take over, and age-related chronic disorders are likely to follow. The physiological consequences can be wide ranging, potentially wreaking havoc on the brain, eye, kidney, muscle, and more. Central nervous system disorders, neurodegenerative in nature, and especially those affecting the myelin sheath, represent worthy targets for advancing therapies that act upon Klotho pathways. Current drugs for these diseases, even therapeutics that are disease modifying rather than treating only the symptoms, leave much room for improvement. It is thus no wonder that this topic has caught the attention of biomedical researchers around the world.
\end{abstract}

Keywords: amyotrophic lateral sclerosis; Klotho; mitochondria; multiple sclerosis; neurodegenerative disease

${ }^{1}$ Department of Pharmaceutical Chemistry, School of Pharmacy, University of California San Francisco, San Francisco, San Francisco, California.

${ }^{2}$ ShangPharma Innovation, Inc., South San Francisco, California.

${ }^{3}$ Department of Medicine and ${ }^{4}$ Cancer Research Center, Boston University School of Medicine, Boston, Massachusetts.

${ }^{5}$ Department of Ophthalmology, New York University School of Medicine, New York, New York.

${ }^{6}$ Department of Chemistry, McGill University, Montreal, Canada.

${ }^{7}$ Hellenic Republic, Ministry of Foreign Affairs, Athens, Greece.

${ }^{8}$ Department of Medicine, Tufts University School of Medicine, St. Elizabeth's Medical Center, Boston, Massachusetts.

${ }^{9}$ Advanced Dental Associates of New England, Woburn, Massachusetts.

${ }^{10}$ Department of Pathobiology, College of Veterinary Medicine, Auburn University, Auburn, Alabama.

${ }^{11}$ Department of Health Sciences, Boston University, Boston, Massachusetts.

${ }^{12}$ Department of Anatomy, Boston University School of Medicine, Boston, Massachusetts.

${ }^{13}$ Department of Ophthalmology, Harvard Medical School, Boston, Massachusetts.

${ }^{14}$ Beetham Eye Institute, Joslin Diabetes Center, Boston, Massachusetts.

${ }^{15}$ PhenoMatriX, Inc., Natick, Massachusetts.

${ }^{16}$ Retina Service, Angiogenesis Laboratory, Massachusetts Eye and Ear Infirmary, Boston, Massachusetts.

*Address correspondence to: Walter H. Moos, PhD, Department of Pharmaceutical Chemistry, School of Pharmacy, University of California San Francisco, UCSF Box 2280, 600 16th Street, Genentech Hall S512D, San Francisco, CA 94143, E-mail: walter.moos@ucsf.edu; or Krishna Kodukula, PhD, ShangPharma Innovation, Inc., 280 Utah Avenue, South San Francisco, CA 94080, E-mail: kkodukula@spiivc.com; or Xiaohong Chen, MD, Retina Service, Angiogenesis Laboratory, Massachusetts Eye and Ear Infirmary, 243 Charles Street, Boston, MA 02114, E-mail: xiaohong_chen@meei.harvard.edu

(C) Walter H. Moos et al. 2020; Published by Mary Ann Liebert, Inc. This Open Access article is distributed under the terms of the Creative Commons License (http://creativecommons.org/licenses/by/4.0), which permits unrestricted use, distribution, and reproduction in any medium, provided the original work is properly cited. 


\section{Background}

The term "epigenetics" refers to changes resulting from modification of gene expression instead of alterations in the genetic code. ${ }^{1}$ We postulate that drugs aimed at inducing endogenous Klotho activity and expression -that is, therapeutics acting through epigenetic mechanisms - should promote remyelination and/or stimulate myelin repair by acting on mitochondrial function. As such, this approach may herald a life-saving path forward for patients suffering from neuroinflammatory diseases.

Klotho-a gene set of three members: $\alpha$-Klotho, $\beta$-Klotho, and $\gamma$-Klotho ${ }^{2-4}$-is aptly named in the biological context of aging. ${ }^{5,6}$ According to Greek mythology, Klotho (or Clotho; Greek: $\mathrm{K} \lambda \omega \theta \dot{\omega})$, the youngest of the Fates (Clotho, Lachesis: $\Lambda \alpha \dot{\alpha} \chi \sigma \sigma l \varsigma$ and Atropos: A $\tau \rho o \pi \circ \varsigma$ ), is one of the three daughter deities (the spinner) of Zeus and Nyx (Nóz, the goddess of night) or Themis ( $\Theta \dot{\varepsilon} \mu l \varsigma$, the goddess of law and order) who together spin out the thread of life, allot destiny, and choose the time of passing for both mortals and immortals. ${ }^{7}$ Thus, nothing could be more appropriate than Klotho serving as a longevity gene. Indeed, once Klotho fails to adequately express its proteins and variants, ${ }^{6,8-10}$ it is implicated in pathways that drive agerelated chronic disorders such as kidney disease, tissue dysfunction, diabetic retinopathies, neurodegeneration, and impairments in mitochondrial function and muscle regeneration. ${ }^{4,8,11-16}$

$\alpha$-Klotho is often referred to as an "anti-aging protein." $3,6,17,18$ When overexpressed in mice, Klotho extends life (20-30\%), reduces oxidative stress (OS), and demonstrates other prosurvival properties. ${ }^{19-25}$ The potential of extending these results to humans has captured pharmaceutical interest in developing Klotho-based therapeutics to hinder the degenerative illnesses of aging. ${ }^{5,6,8,26-28}$

Noticeably, a growing body of evidence asserts the therapeutic potential of Klotho in treating neurodegenerative diseases. As population aging is a global phenomenon, ${ }^{29}$ age-related neurodegenerative disorders are projected to surpass cancer as the foremost cause of death after cardiovascular disease in the developed world within 20 years. ${ }^{30}$ The late-onset sporadic form (LOAD) of Alzheimer's disease (AD) $)^{31-33}$ accounts for $>90 \%$ of disease cases. ${ }^{31,34-36}$ Along with advanced aging, ${ }^{23,37-43}$ inheritance of the apolipoprotein E4 allele (also called APOE4 or APOE\&4) remains the most significant known genetic risk factor for LOAD. The risk is higher and the age at onset of dementia is younger for individuals carrying multiple copies of APOE4, whereas other APOE alleles are considered protective. ${ }^{31,32,44}$ In a study of a gene variant of Klotho with respect to $\mathrm{AD}$ in at-risk but presymptomatic individuals, heterozygosity was found to reduce amyloid aggregation in an APOE4-associated manner. ${ }^{45}$ Of interest, in a research analysis that measured Klotho concentrations in the cerebrospinal fluid of $\mathrm{AD}$ subjects and in older versus younger adults, Klotho levels were found to be lower in women compared with men. ${ }^{46,47}$ Perhaps the latter observation may help to explain why women are more likely than men to have $\mathrm{AD}$, although the reported difference may be the result of biological or social artifacts. ${ }^{48}$ In addition to $\mathrm{AD}$, the most common neurodegenerative disease, Parkinson's disease (PD), the second most common neurodegenerative disease, ${ }^{49}$ has also been tied to Klotho pathways. ${ }^{50-52}$

Beyond $\mathrm{AD}$ and $\mathrm{PD}$, age-related declines in Klotho ${ }^{8,13,17,24,53}$ are associated with a range of other deteriorating central nervous system (CNS) processes. ${ }^{17,24}$ For example, mounting evidence implicates dysregulation of Klotho in shared mechanistic pathological relationships linking iron and myelin in various common and rare brain diseases, ${ }^{54-56}$ including abnormalities in myelination and the maturation of oligodendrocytes that are central to the pathogenicity of diseases such as multiple sclerosis (MS) ${ }^{26,56,57}$ and amyotrophic lateral sclerosis (ALS). ${ }^{56,58}$

\section{OS Demyelination and Mitochondrial Dysfunction}

Mitochondrial dysfunction is a well-documented enabling factor in the pathophysiology of neurological conditions and disorders (Fig. 1). ${ }^{41,59-68}$ Although a principal role of mitochondria is to supply the bioenergy needed for cellular processes and maintenance, ${ }^{69-71}$ mitochondria also help regulate neurite branching and regeneration as well as synaptic strength, stability, and signaling in the CNS. ${ }^{72}$ In addition, myelin repair is intimately dependent on healthy mitochondrial function within the CNS in oligodendrocytes and neuronal cell bodies. $^{63,64,73-77}$

Dysfunctional mitochondria become sources of reactive oxygen species (ROS) that contribute to OS with deleterious effects on the cell's wellbeing. ${ }^{61,70,71,74,77-80}$ Manifestations of OS are hallmark symptoms in neurological disease, including cognitive deficits. ${ }^{52,54,65,76,79,81-88}$ In concert with the above, a correlation was found between OS in the CNS and demyelination, which results in the loss of integrity 


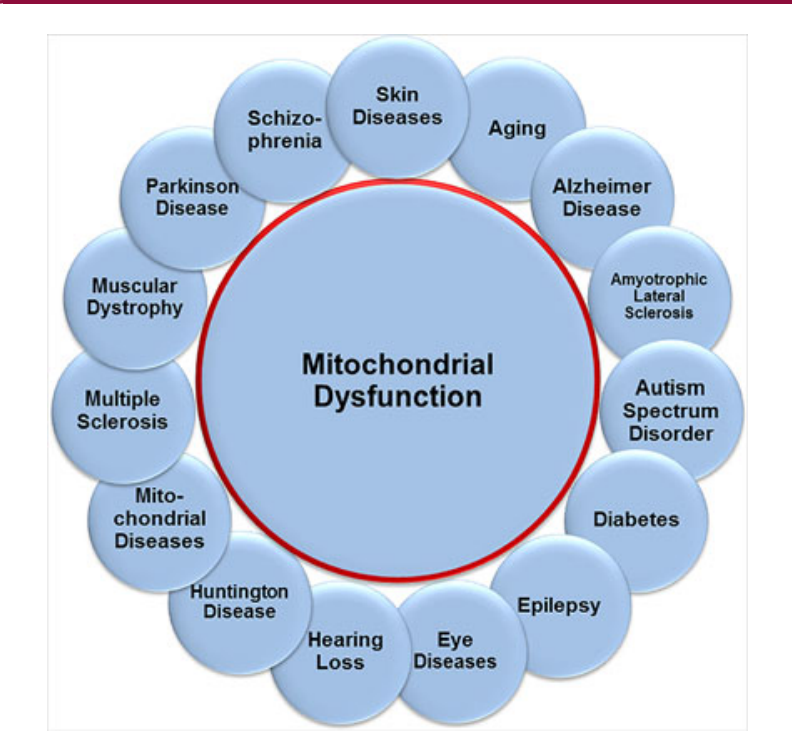

FIG. 1. Sampling of neurologic conditions associated with mitochondrial dysfunction.

and proper maintenance of oligodendrocytes and their myelin sheaths, the latter being crucial for cognitive performance and higher brain function. ${ }^{57,89-91}$

Thus, inclusion of strategies for enhancing mitochondrial biogenesis, function, and protection ${ }^{68,80,92-96}$ that may also rely on pathways epigenetically induced by $\operatorname{diet}^{97-108}$ and/or exercise ${ }^{99,100,106-109}$ can be timely in the therapeutic protocols for treating myelination disorders. ${ }^{68,73-76,98,104,110-115}$

\section{Dysregulated Myelination in Peripheral and CNS Diseases}

Microglia are a distinct population of immune cells in the CNS. ${ }^{116-118}$ They execute fundamental tasks in brain development, physiology, and homeostasis and in influencing the pathological progression of brain diseases. ${ }^{117-122}$ There is evidence to suggest that microglia actively remove damaged myelin ${ }^{114,123}$ to recruit myelinating cells, oligodendrocytes in the CNS, and Schwann cells in the peripheral nervous system (PNS) to repair the injured myelin sheath. ${ }^{114,117,118,123-125}$ Dysregulated myelination is a characteristic feature of numerous heritable neurological diseases, such as the PNS hereditary disorder, Charcot-Marie-Tooth disease, ${ }^{126,127}$ X-linked adrenoleukodystrophy and metachromatic leukodystrophy, ${ }^{128}$ hereditary diffuse leukoencephalopathy with spheroids, Nasu-Hakola disease, ${ }^{114}$ and Huntington's disease, ${ }^{129,130}$ among others. ${ }^{55,131,132}$ A dysfunctional myelination apparatus is also evident in acquired demyelinating diseases such as diabetic peripheral neuropathy, drug-related peripheral neuropathies, leprosy, and peripheral neuropathies of inflammatory etiology. ${ }^{132}$

Most interestingly, converging evidence drawn from "Big Data" analytics in parallel with epigenetic, neuroimaging, and experimental model investigations seems to connect an adult-onset form of attention-deficit/ hyperactivity disorder pathogenesis and persistence with dysregulated myelination. ${ }^{133,134}$ Many risk genes for CNS disorders such as AD, PD, schizophrenia, autism, and MS have been unveiled by genome-wide association studies to be expressed by microglia. ${ }^{117}$ Dysfunction of microglia is common in neurological diseases $^{114}$ and recent studies have found that sex differences in microglial gene expression and functions seen in young adult mice tend to be increasingly pronounced in the aging brain. ${ }^{135}$

\section{Klotho as an Obligatory Co-receptor}

High concentrations of phosphate in the body are found in bone, teeth, and dental enamel as calcium phosphate crystals. ${ }^{136,137}$ Klotho regulates phosphorus and calcium homeostasis $5,6,18,23,138$ and functions as an obligatory co-receptor that binds and activates its related endocrine fibroblast growth factor (FGF) receptors (FGFRs) to potentiate its biological activities. $5,6,23,102,139-146$ FGFs are exemplary pleiotropic hormones that play numerous roles in cellular and metabolic homeostasis. ${ }^{5,6,137,141,144-148}$ In particular, FGF23 is a bone-derived hormone that in conjunction with Klotho acts on the kidney to increase phosphate excretion and suppress biosynthesis of vitamin D. ${ }^{5,6,14,23,102,136,138,145,148,149}$ Vitamin D regulates epigenetic mechanisms that maintain the transcription of its target genes in regulatory networks, including the expression of Klotho and nuclear factor-erythroid-2related factor 2 (Nrf2) to carry out many of its homoeostatic functions. ${ }^{17,97,150-153}$ Vitamin D is a modulator of the immune system, ${ }^{154,155}$ hence its mention here, and accumulating evidence suggests vitamin $\mathrm{D}$ deficiency is a risk factor for dysregulated Klotho-associated neurodegenerative diseases, the most noteworthy being MS. ${ }^{9,27,52,97,102,150,152,153,156-158}$

\section{Multiple Sclerosis}

MS is an insidious progressive neurodegenerative disease characterized by demyelinated lesions throughout the brain, spinal cord, and optic nerve resulting from immune-mediated attacks against myelin. ${ }^{159-165}$ It is 
<smiles>COC(=O)/C=C/C(=O)[O-]</smiles>

Monomethyl fumarate (MMF)<smiles>COC(=O)/C=C/C(=O)OC</smiles>

Dimethyl fumarate (Tecfidera)<smiles>COC(=O)/C=C/C(=O)OCCN1C(=O)CCC1=O</smiles>

Diroximel fumarate (Vumerity)

FIG. 2. Monomethyl fumarate, the pharmacologically active form of Tecfidera and Vumerity.

the apotheosis of myelination disorders that affects $\sim 2.5$ million people around the world ${ }^{166-168}$ and currently there are no definitive cures. The standard of chronic care, after using steroids for acute episodes, centers on the use of disease modifying therapies (DMTs) that modulate an overactive immune response, such as antibodies against interferon, interleukin, or related $\mathrm{T}$ cell targets. ${ }^{9,169-172}$ Unfortunately, although there is a growing armamentarium of DMTs for neurodegenerative diseases, they have to date had only a modest impact on disease progression ${ }^{173,174}$ and thus the demand for myelin repair-promoting therapies for MS remains a significant unmet medical need. ${ }^{159,175-178}$

The discovery of new drugs is a daunting, lengthy, and costly endeavor. Drug repurposing-based on mechanism of action and/or biological activity, not uncommonly the result of serendipity-is a promising and cost-saving approach for the treatment of rare genetic diseases and diseases with limited therapeutic options. ${ }^{90,104,179,180}$ This approach has yielded derivatives of the simple organic chemical, fumarate, including Vumerity (diroximel fumarate), which is reported to be better tolerated than Tecfidera, with fewer gastrointestinal side effects and more favorable pharmacokinetic properties. Vumerity is a delayed release formulation of an inactive diester prodrug of mono- methyl fumarate (Fig. 2). Both Vumerity and Tecfidera are converted into the same pharmacologically active drug, monomethyl fumarate in vivo. ${ }^{94,163}$ The medical potential of dimethyl fumarate was identified over 60 years ago and marketed for the treatment of psoriasis. ${ }^{181,182}$ MS therapeutics approved by the U.S. Food and Drug Administration (FDA) are given in Table 1.

\section{Klotho Structure, Distribution, and Function in MS}

Klotho is a single-pass transmembrane protein expressed in the brain (hippocampus and choroid plexus), kidney, eye (retina, optic nerve, lens) and parathyroid gland, and less so in other tissues. ${ }^{3,18,27,102,183,184} \mathrm{~A}$ soluble form of Klotho (sKlotho), primarily secreted from the kidney, circulates in blood, urine, and cerebrospinal fluid, exerting different biological effects in multiple tissues as a humoral factor. ${ }^{5,6,8,52,185-189}$

In the eye, Klotho protects against $\mathrm{OS}^{53,55,58,153,190,191}$ and is essential to the proper maintenance and function of the ocular system, ${ }^{12,26,192-195}$ being expressed throughout the retina, with the highest levels in retinal ganglion cells. ${ }^{196}$ The retinal pigment epithelium (RPE) is a highly specialized CNS tissue whose function is critical in preserving retinal homeostasis ${ }^{53,78}$ and an age-dependent decline of Klotho expression is said to

Table 1. Food and Drug Administration-Approved Drugs for Multiple Sclerosis in Disease Modifying Therapies

\begin{tabular}{lll}
\hline Older drugs, year approved & \multicolumn{1}{c}{ Recent approvals, year } & Withdrawals, year \\
\hline Betaseron (INF- $\beta$-1b), 1993 & Lemtrada (alemtuzumab), 2014 & Zinbryta (daclizumab), 2018 \\
Avonex (INF- $\beta$-1a), 1996 & Plegridty (INF- $\beta$-1a), 2014 & \\
Copaxone (glatiramer acetate), 1996 & Glatopa (glatiramer acetate), 2015 & \\
Rebif (INF- $\beta$-1a), 2002 & Ocrevus (ocrelizumab), 2017 \\
Tysabri (natalizumab), 2004 & Mavenclad (cladribine), 2019 \\
Extavia (INF- $\beta$-1b), 2009 & Mayzent (siponimod), 2019 \\
Gilenya (fingolimod), 2010 & Vumerity (diroximel fumarate), 2019 \\
Aubagio (teriflunomide), 2012 & & \\
Tecfidera (dimethyl fumarate) 2013 & & \\
\hline
\end{tabular}

Sources: FDA Drug Approvals and Databases (www.fda.gov/drugs/development-approval-process-drugs/drug-approvals-and-databases). Orange Book: Approved Drug Products with Therapeutic Equivalence Evaluations (www.accessdata.fda.gov/scripts/cder/ob/index.cfm).

FDA, Food and Drug Administration. 
Table 2. Food and Drug Administration-Approved Drugs for Treating Amyotrophic Lateral Sclerosis

\begin{tabular}{|c|c|c|}
\hline $\begin{array}{l}\text { Glutamate } \\
\text { antagonist }\end{array}$ & Antioxidant & Other drugs \\
\hline $\begin{array}{l}\text { Riluzole } \\
\quad \text { (Rilutek/ } \\
\text { Teglutik) }\end{array}$ & $\begin{array}{l}\text { Edaravone } \\
\quad \text { (Radicava/ } \\
\text { Radicut) }\end{array}$ & $\begin{array}{l}\text { Dextromethorphan hydrobromide/ } \\
\text { quinidine sulfate (Neudexta) } \\
\text { for pseudobulbar affect }\end{array}$ \\
\hline
\end{tabular}

Sources: FDA Drug Approvals and Databases (www.fda.gov/drugs/ development-approval-process-drugs/drug-approvals-and-databases). Orange Book: Approved Drug Products with Therapeutic Equivalence Evaluations (www.accessdata.fda.gov/scripts/cder/ob/index.cfm).

contribute to RPE degeneration and retinal pathology. ${ }^{53}$ Apoptotic cells in models of retinal degeneration were found to exhibit high levels of Klotho, ${ }^{8}$ which is consistent with Klotho overexpression in its role as a protective protein that inhibits apoptosis. ${ }^{22,197,198}$ A recent study has shown that higher levels of circulating Klotho protein is protective in patients with diabetic retinopathy. ${ }^{199}$

Although the retina itself is a nonmyelinated tissue, ${ }^{200}$ optic neuritis, a disease affecting the myelinated part of retinal ganglion cell axons, is a serious and often difficult to assess manifestation of MS, ${ }^{201}$ particularly in the pediatric population. ${ }^{202}$ More than $70 \%$ of MS patients suffer vision loss as a secondary effect of optic neuritis disease progression. ${ }^{160,203,204}$ In recent studies, Klotho was shown to accelerate remyelination in a cuprizone-mediated demyelination mouse model. ${ }^{9,28}$ This important finding is refocusing attention on Klotho's role in neurodegeneration and research efforts are increasingly directed toward the develop- ment of MS treatments that promote remyelination and/or stimulate myelin repair. ${ }^{9,27,28,112,166,169,205-211}$ However, because Klotho does not cross the bloodbrain barrier, ${ }^{10,212}$ a small molecule approach aimed at inducing endogenous Klotho activity and expression in the CNS is surfacing as a promising therapeutic strategy. ${ }^{27,81,90,143,213,214}$ Epigenetics ${ }^{10,90,100,169,215-219}$ and gene therapy-based methods are part of the emerging landscape under investigation. ${ }^{19,215,220,221}$

\section{Amyotrophic Lateral Sclerosis}

The global prevalence of ALS is estimated to be roughly two to four cases per 100,000 population ${ }^{222,223}$ compared with $\sim 30$ cases per 100,000 population for MS. ${ }^{168}$ ALS (also referred to as progressive muscular atrophy or Lou Gehrig's disease) is a devastating neurodegenerative disease. It damages motor neurons in the brain and spinal cord leading to progressive muscle atrophy and paralysis that is fatal, usually within 3-5 years of diagnosis. ${ }^{58,224-227}$ Unfortunately, patients with ALS, at present, have limited therapeutic options (Table 2). ${ }^{96,173,228}$ Moreover, given the rapid and terminal progression of the disease postdiagnosis, there is a pressing need to develop new therapies and/or based on mechanism of action repurposing drugs already approved for other diseases. ${ }^{176,180}$ Recruiting ALS subjects into traditional clinical trials is challenging because of the low number of cases in the population. Trial-design protocols ${ }^{229}$ that rely on restrictive inclusion criteria, frequent study visits, use of a placebo
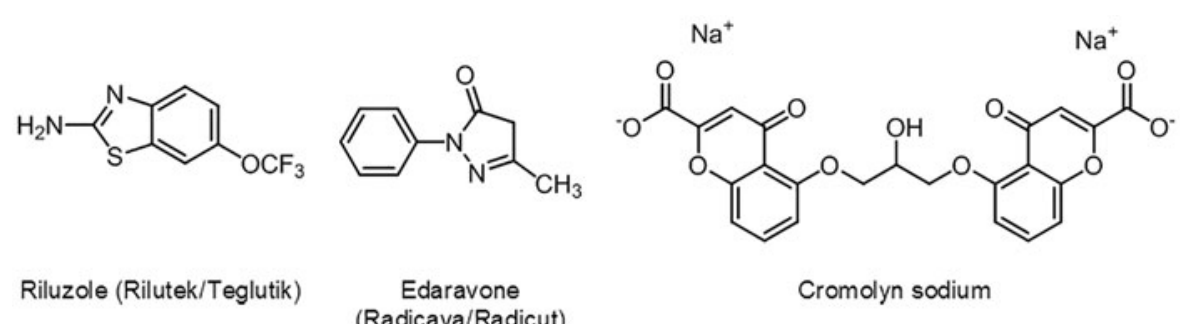

(Radicava/Radicut)

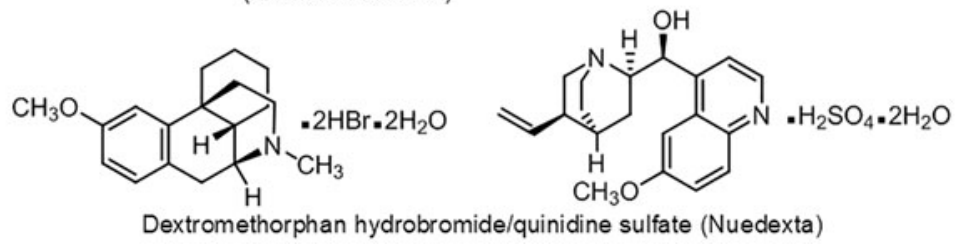

FIG. 3. Chemical structures of FDA-approved therapeutics for ALS, including cromolyn sodium, a drug used to treat asthma and other conditions showing promising potential as a repurposed drug for ALS. ALS, amyotrophic lateral sclerosis; FDA, Food and Drug Administration. 


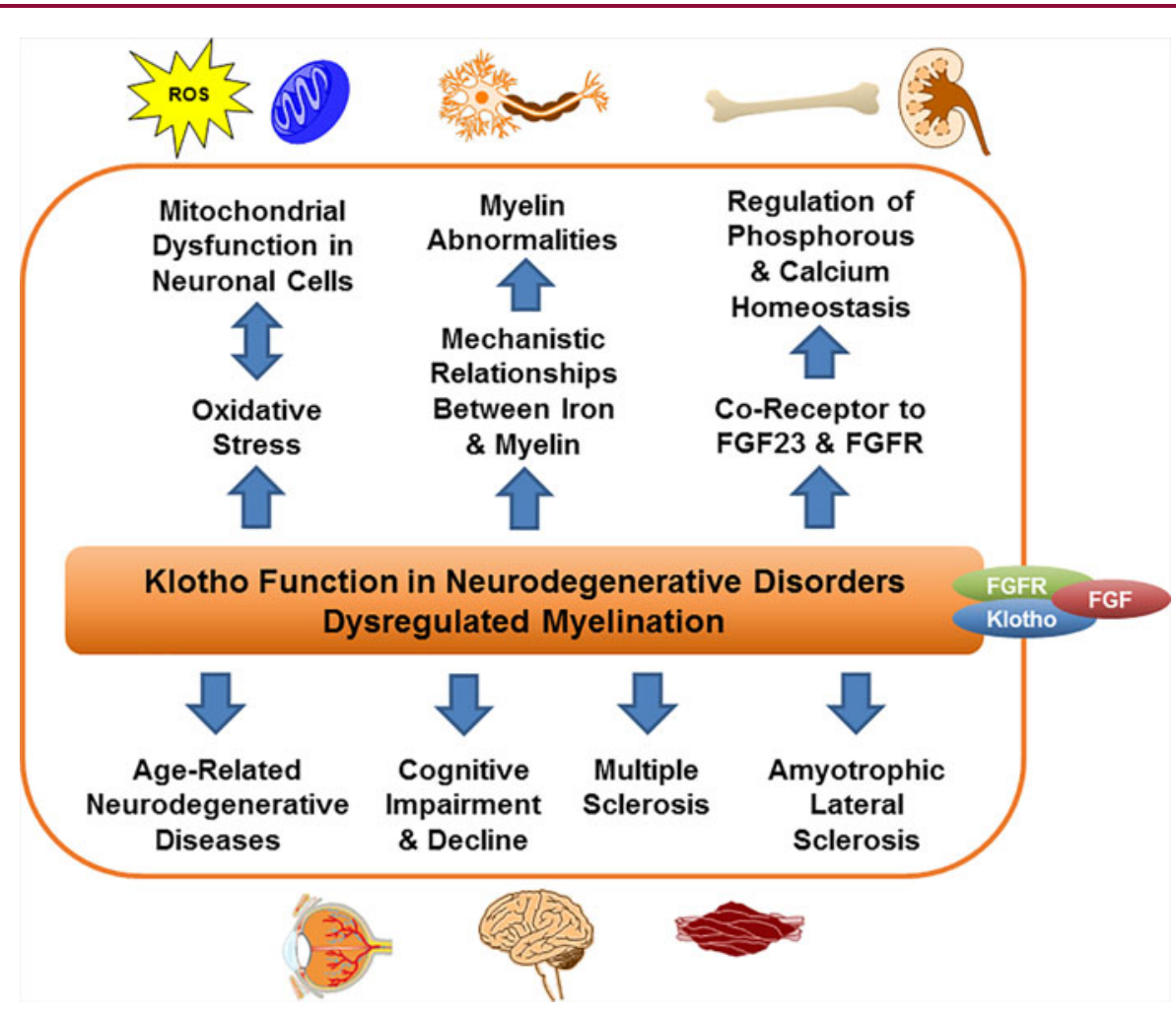

FIG. 4. Klotho function in neurodegenerative disorders and/or dysregulated myelination.

control arm that denies patients early access to the therapy, and the comparatively long time it takes to document results relative to the rapid progression of the disease are additional impediments. ${ }^{230}$

Riluzole and edaravone, the principal therapeutics used in the treatment of ALS (Fig. 3), have a modest impact on disease progression, extending survival by $\sim 3$ months. ${ }^{68,96,223,231}$ The combination of dextromethorphan and quinidine sulfate has shown positive results against pseudobulbar affect (emotional lability) and is FDA-approved for ALS and $\mathrm{MS},{ }^{232}$ although it is reported to be prescribed more to patients suffering from dementia or PD. ${ }^{233}$ Clearly, much more effective therapies are needed and a vigorous research effort has been underway for the past several years to screen for and develop new pharmaceuticals for treating neurodegenerative diseases including ALS. ${ }^{234,235}$ Cromolyn sodium (Fig. 3), an FDA-approved compound used to treat asthma and other conditions has recently emerged as a promising new therapeutic for ALS. In the SOD $1^{\mathrm{G} 93 \mathrm{~A}}$ mouse model of ALS, treatment with cromolyn sodium delayed disease onset and showed neuroprotection by decreasing the inflammatory re- sponse. ${ }^{236}$ However, a focus on myelination may lead to more lasting and effective therapeutic outcomes. Klotho overexpression in the SOD $1^{\mathrm{G} 93 \mathrm{~A}}$ mouse model was shown to suppress the production of proinflammatory cytokines, reduce the expression of neuroinflammatory markers, and prevent neuronal loss with a more profound effect in the spinal cord than in the motor cortex, thereby delaying the onset and progression of the disease. ${ }^{58}$ These results along with the positive effect Klotho has on the promyelinating properties of oligodendrocytes offer compelling evidence in support of developing Klotho-based therapeutic strategies for treating ALS. ${ }^{58}$

\section{Concluding Remarks}

As outlined in the introduction, drugs aimed at inducing endogenous Klotho activity and expression-epigenetic action per se-should promote remyelination and/or stimulate myelin repair by acting on mitochondrial function. In the ensuing two decades since the serendipitous discovery of Klotho as an aging-suppressor gene, research has helped unmask many of its functional pathways in neurodegenerative disorders 
and/or dysregulated myelination (Fig. 4). Deficient levels of Klotho protein lead to excessive OS induction mainly from ROS produced in mitochondrial dysfunction. Myelin repair is intimately dependent on the energy made available by healthy mitochondria within the CNS in oligodendrocytes (Schwann cells in the PNS) and neuronal cell bodies. Thus, drugs aimed at inducing endogenous Klotho production may herald a life-saving path forward for patients suffering from neuroinflammatory diseases. In parallel, much as the old psoriasis drug, dimethyl fumarate, was repurposed to treat MS, more drug repurposing may find worthwhile paths here too. Will AD, PD, MS, or ALS yield to these approaches when coupled with drugs that attack such a powerful pathway as Klotho? As we kick off what we hope will be "the roaring 2020s" when it comes to the advancement of major new life-saving therapeutics, time and effort toward this goal will hopefully give us the answers.

\section{Acknowledgments}

The authors gratefully acknowledge the generous financial support from the Foundation for a Cure for Mitochondrial Disease, Inc. (MitoCure). This article is dedicated to Dr. Brenda Milner on the occasion of her $102^{\text {nd }}$ birthday.

\section{Authors' Contribution}

Authorship has been based on the principles of the International Committee of Medical Journal Editors: substantial contributions to the conception or design of the work or the acquisition, analysis or interpretation of data for the work; drafting the work or revising it critically for important intellectual content; final approval of the version to be published; and agreement to be accountable for all aspects of the work in ensuring that questions related to the accuracy or integrity of any part of the work are appropriately investigated and resolved.

\section{Author Disclosure Statement}

W.H.M., in addition to academic and nonprofit roles, is employed by ShangPharma Innovation, is a managing director of Pandect Bioventures, receives royalties from Elsevier as a book author, is a consultant for Aduro Biotech, receives royalty and equity sharing benefits from SRI International, has stock or other financial interests in Aduro Biotech, Azkarra Therapeutics, Rigel Pharmaceuticals and Valitor, and serves on the boards of directors and/or scientific advisory boards of Aprinoia Therapeutics, Circle Pharma, Global Blood Therapeutics, Rigel Pharmaceuticals, ShangPharma Innovation and Valitor. D.V.F., in addition to academic and nonprofit roles, is employed by Viracta Therapeutics, Phoenicia Biosciences, and Takeda Pharmaceuticals and serves as a consultant to Briacell Therapeutics. Kosta Steliou, in addition to academic and nonprofit roles, is the founder and chief scientific officer of PhenoMatriX. K.K. consults with and/or serves as an executive or on the boards of various biotechnology and pharmaceutical companies from time to time, where he may receive compensation and/or stock options, and he is eligible to receive compensation from ShangPharma Innovation and Pandect Bioventures, health care venture incubator and venture capital firms.

\section{Funding Information}

The Foundation for a Cure for Mitochondrial Disease, Inc. (MitoCure).

\section{References}

1. Noble D. Conrad Waddington and the origin of epigenetics. J Exp Biol. 2015;218:816-818.

2. Jurado-Fasoli L, Amaro-Gahete FJ, De-La-O A, et al. Adherence to the Mediterranean diet, dietary factors, and S-Klotho plasma levels in sedentary middle-aged adults. Exp Gerontol. 2019;119:25-32.

3. Zhang Y, Wang L, Wu Z, et al. The expressions of Klotho family genes in human ocular tissues and in anterior lens capsules of age-related cataract. Curr Eye Res. 2017;42:871-875.

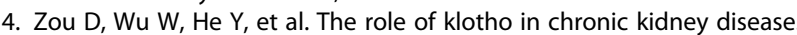
BMC Nephrol. 2018;19:285.

5. Kuro-o, M. Molecular mechanisms underlying accelerated aging by defects in the FGF23-Klotho system. Int J Nephrol. 2018;2018: $1-6$.

6. Kuro-o, M. The Klotho proteins in health and disease. Nat Rev Nephrol. 2019;15:27-44

7. Grant M, Hazel J. Who's Who in Classical Mythology. Oxford University Press: New York, NY, 1993.

8. Cheikhi A, Barchowsky A, Sahu A, et al. Klotho: an elephant in aging research. J Gerontol A Biol Sci Med Sci. 2019;74:1031-1042.

9. Torbus-Paluszczak M, Bartman W, Adamczyk-Sowa M. Klotho protein in neurodegenerative disorders. Neurol Sci. 2018;39:1677-1682.

10. Wolf EJ, Morrison FG, Sullivan DR, et al. The goddess who spins the thread of life: Klotho, psychiatric stress, and accelerated aging. Brain Behav Immun. 2019;80:193-203.

11. Kan W-C, Hwang J-Y, Chuang L-Y, et al. Effect of osthole on advanced glycation end products-induced renal tubular hypertrophy and role of klotho in its mechanism of action. Phytomedicine. 2019;53:205-212.

12. Nusinovici S, Sabanayagam C, Teo BW, et al. Vision impairment in CKD patients: epidemiology, mechanisms, differential diagnoses, and prevention. Am J Kidney Dis. 2019;73:846-857.

13. Sahu A, Mamiya $H$, Shinde $S N$, et al. Age-related declines in $\alpha$-Klotho drive progenitor cell mitochondrial dysfunction and impaired muscle regeneration. Nat Commun. 2018;9:4859.

14. Smith ER, Holt SG, Hewitson TD. aKlotho-FGF23 interactions and their role in kidney disease: a molecular insight. Cell Mol Life Sci. 2019;76: 4705-4724.

15. Wehling-Henricks M, Welc SS, Samengo G, et al. Macrophages escape Klotho gene silencing in the mdx mouse model of Duchenne muscular dystrophy and promote muscle growth and increase satellite cell numbers through a Klotho-mediated pathway. Hum Mol Genet. 2018; 27:14-29. 
16. Welc SS, Wehling-Henricks M, Kuro-o M, et al. Modulation of Klotho expression in injured muscle perturbs Wnt signaling and influences the rate of muscle growth. Exp Physiol. 2020;105:132-147.

17. Cararo-Lopes MM, Mazucanti CHY, Scavone C, et al. The relevance of $\alpha$-KLOTHO to the central nervous system: some key questions. Ageing Res Rev. 2017;36:137-148.

18. Jia G, Aroor AR, Jia C, et al. Endothelial cell senescence in aging-related vascular dysfunction. BBA Mol Basis Dis. 2019;1865:1802-1809.

19. Chen C-D, Zeldich E, Li Y, et al. Activation of the anti-aging and cognition-enhancing gene Klotho by CRISPR-dCas9 transcriptional effector complex. J Mol Neurosci. 2018;64:175-184.

20. Isaev NK, Stelmashook EV, Genrikhs EE. Neurogenesis and brain aging. Rev Neurosci. 2019;30:573-580.

21. Kurosu $H$, Yamamoto $M$, Clark JD, et al. Suppression of aging in mice by the hormone Klotho. Science. 2005;309:1829-1833.

22. Mytych J, Wos I, Solek P, et al. Protective role of klotho protein on epithelial cells upon co-culture with activated or senescent monocytes. Exp Cell Res. 2017;350:358-367.

23. Paroni G, Panza F, Cosmo SD, et al. Klotho at the edge of Alzheimer's disease and senile depression. Mol Neurobiol. 2018;56:1908-1920.

24. Vo HT, Laszczyk AM, King GD. Klotho, the key to healthy brain aging? Brain Plast. 2018;3:183-194.

25. Yamamoto M, Clark JD, Pastor JV, et al. Regulation of oxidative stress by the anti-aging hormone Klotho. J Biol Chem. 2005;280:3802938034.

26. Chen $\mathrm{C}$, Sloane JA, $\mathrm{Li} \mathrm{H}$, et al. The antiaging protein Klotho enhances oligodendrocyte maturation and myelination of the CNS. J Neurosci. 2013;33:1927-1939.

27. Göttle $P$, Förster $M$, Weyers $V$, et al. An unmet clinical need: roads to remyelination in MS. Neurol Res Pract. 2019;1:21.

28. Zeldich E, Chen C-D, Avila R, et al. The anti-aging protein Klotho enhances remyelination following cuprizone-induced demyelination. J Mol Neurosci. 2015;57:185-196.

29. United Nations, Department of Economic and Social Affairs, Population Division (2019). World Population Ageing 2019: Highlights (ST/ESA/ SER.A/430).

30. Telling GC. Breakthroughs in antemortem diagnosis of neurodegenerative diseases. Proc Natl Acad Sci U S A. 2019;116:22894-22896.

31. Belloy ME, Napolioni V, Greicius MD. A quarter century of APOE and Alzheimer's disease: progress to date and the path forward. Neuron. 2019;101:820-838.

32. Ferri $E$, Gussago C, Casati M, et al. Apolipoprotein E gene in physiological and pathological aging. Mech Ageing Dev. 2019;178:41-45.

33. Therriault J, Benedet AL, Pascoal TA, et al. Association of apolipoprotein $\mathrm{E} \varepsilon 4$ with medial temporal tau independent of amyloid- $\beta$. JAMA Neurol. 2020 [Epub ahead of print]; DOI: 10.1001/jamaneurol.2019.4421

34. Durmaz A, Kumral E, Durmaz B, et al. Genetic factors associated with the predisposition to late onset Alzheimer's disease. Gene. 2019;707:212215.

35. Madmoli M, Modheji Y, Rafi A, et al. Diabetes and its predictive role in the incidence of Alzheimer's disease. Med Sci. 2019;23:30-34

36. Raulin A, Kraft L, Al-Hilaly YK, et al. The molecular basis for apolipoprotein $\mathrm{E} 4$ as the major risk factor for late-onset Alzheimer's disease. J Mol Biol. 2019;431:2248-2265.

37. Currais A, Huang L, Goldberg J, et al. Elevating acetyl-CoA levels reduces aspects of brain aging. eLife. 2019;8:e47866.

38. Dzau VJ, Inouye SK, Rowe JW, et al. Enabling healthful aging for all-The National Academy of Medicine Grand Challenge in Healthy Longevity. N Engl J Med. 2019;381:1699-1701.

39. Hara Y, McKeehan N, Fillit HM. Translating the biology of aging into novel therapeutics for Alzheimer disease. Neurology. 2018;92:84-93.

40. Hou Y, Dan X, Babbar M, et al. Ageing as a risk factor for neurodegenerative disease. Nat Rev Neurol. 2019;15:565-581.

41. Irwin $\mathrm{MH}$, Moos WH, Faller DV, et al. Epigenetic treatment of neurodegenerative disorders: alzheimer and Parkinson diseases. Drug Dev Res. 2016;77:109-123.

42. Poddar J, Pradhan M, Ganguly G, et al. Biochemical deficits and cognitive decline in brain aging: intervention by dietary supplements. J Chem Neuroanat. 2019;95:70-80.

43. Wegmann S, Bennett RE, Delorme L, et al. Experimental evidence for the age dependence of tau protein spread in the brain. Sci Adv. 2019;5: eaaw6404.
44. Arboleda-Velasquez JF, Lopera F, et al. Resistance to autosomal dominant Alzheimer's disease in an APOE3 Christchurch homozygote: a case report. Nat Med. 2019;25:1680-1683.

45. Erickson CM, Schultz SA, Oh JM, et al. KLOTHO heterozygosity attenuates APOE4-related amyloid burden in preclinical AD. Neurology. 2019;92: e1878-e1889.

46. Dote-Montero M, Amaro-Gahete FJ, De-La-O A, et al. Study of the association of DHEAS, testosterone and cortisol with S-Klotho plasma levels in healthy sedentary middle-aged adults. Exp Gerontol. 2019;121: 55-61.

47. Semba RD, Moghekar AR, Hu J, et al. Klotho in the cerebrospinal fluid of adults with and without Alzheimer's disease. Neurosci Lett. 2014;558:37-40.

48. Alzheimers Association. (2019). Alzheimer's disease facts and figures. Alzheimer's Dement. 2019;15:321-387.

49. Dawson VL, Dawson TM. Promising disease-modifying therapies for Parkinson's disease. Sci Transl Med. 2019;11:eaba1659.

50. Baluchnejadmojarad T, Eftekhari S-M, Jamali-Raeufy N, et al. The anti-aging protein klotho alleviates injury of nigrostriatal dopaminergic pathway in 6hydroxydopamine rat model of Parkinson's disease: involvement of PKA/CaMKII/CREB signaling. Exp Gerontol. 2017;100:70-76.

51. Leon J, Moreno AJ, Garay Bl, et al. Peripheral elevation of a Klotho fragment enhances brain function and resilience in young, aging, and $\alpha$-synuclein transgenic mice. Cell Rep. 2017;20:1360-1371.

52. Pathare G, Shalia K. Klotho: an emerging factor in neurodegenerative diseases. Biomed Res J. 2019;6:1-6.

53. Kokkinaki M, Abu-Asab M, Gunawardena N, et al. Klotho regulates retinal pigment epithelial functions and protects against oxidative stress. J Neurosci. 2013;33:16346-16359.

54. Cioffi F, Adam RHI, Broersen K. Molecular mechanisms and genetics of oxidative stress in Alzheimer's disease. J Alzheimers Dis. 2019;72:981-1017.

55. Heidari M, Gerami SH, Bassett B, et al. Pathological relationships involving iron and myelin may constitute a shared mechanism linking various rare and common brain diseases. Rare Dis. 2016:4:e1198458.

56. Wellman SM, Cambi F, Kozai TD. The role of oligodendrocytes and their progenitors on neural interface technology: a novel perspective on tissue regeneration and repair. Biomaterials. 2018;183:200-217.

57. Adamczyk B, Adamczyk-Sowa M. New insights into the role of oxidative stress mechanisms in the pathophysiology and treatment of multiple sclerosis. Oxid Med Cell Longev. 2016;2016:1973834.

58. Zeldich E, Chen C-D, Boden E, et al. Klotho is neuroprotective in the superoxide dismutase (SOD1G93A) mouse model of ALS. J Mol Neurosci. 2019;69:264-285

59. Carter $C$. Autism genes and the leukocyte transcriptome in autistic toddlers relate to pathogen interactomes, infection and the immune system. A role for excess neurotrophic sAPP $\alpha$ and reduced antimicrobial A $\beta$. Neurochem Int. 2019;126:36-58.

60. Gautam M, Xie EF, Kocak N, et al. Mitoautophagy: a unique selfdestructive path mitochondria of upper motor neurons with TDP-43 pathology take, very early in ALS. Front Cell Neurosci. 2019;13:489.

61. Hoffman ME, Augsburger BN, Foradori CD, et al. Neuroprotective effects of carnitinoid compounds in rodent cellular and in vivo models of mitochondrial complex I dysfunction. Curr Anal Biotechnol. 2019;2: 26-33.

62. Lou G, Palikaras K, Lautrup S, et al. Mitophagy and neuroprotection. Trends Mol Med. 2020;26:8-20.

63. Madsen PM, Pinto M, Patel S, et al. Mitochondrial DNA double-strand breaks in oligodendrocytes cause demyelination, axonal injury, and CNS inflammation. J Neurosci. 2017;37:10185-10199.

64. McAvoy K, Kawamata H. Glial mitochondrial function and dysfunction in health and neurodegeneration. Mol Cell Neurosci. 2019;101:103417.

65. Moos WH, Maneta $E$, Pinkert CA, et al. Epigenetic treatment of neuropsychiatric disorders: autism and schizophrenia. Drug Dev Res. 2016;77: 53-72.

66. Nellessen A, Nyamoya S, Zendedel A, et al. Nrf2 deficiency increases oligodendrocyte loss, demyelination, neuroinflammation and axonal damage in an MS animal model. Metab Brain Dis. 2020;35:353-362.

67. van Horssen J, van Schaik P, Witte M. Inflammation and mitochondrial dysfunction: a vicious circle in neurodegenerative disorders? Neurosci Lett. 2019;710:132931.

68. Wu Y, Chen M, Jiang J. Mitochondrial dysfunction in neurodegenerative diseases and drug targets via apoptotic signaling. Mitochondrion. 2019; 49:35-45. 
69. Moos WH, Faller DV, Harpp DN, et al. Microbiota and neurological disorders: a gut feeling. BioRes Open Access. 2016;5:137-145.

70. Moos WH, Faller DV, Glavas IP, et al. Epigenetic treatment of neurodegenerative ophthalmic disorders: an eye toward the future. BioRes Open Access. 2017;6:169-181.

71. Moos $\mathrm{WH}$, Pinkert $\mathrm{CA}$, Irwin $\mathrm{MH}$, et al. Epigenetic treatment of persistent viral infections. Drug Dev Res. 2017;78:24-36.

72. Fecher C, Trovò L, Müller SA, et al. Cell-type-specific profiling of brain mitochondria reveals functional and molecular diversity. Nat Neurosci. 2019;22:1731-1742.

73. Campbell G, Licht-Mayer S, Mahad D. Targeting mitochondria to protect axons in progressive MS. Neurosci Lett. 2019;710:134258.

74. de Barcelos IP, Troxell RM, Graves JS. Mitochondrial dysfunction and multiple sclerosis. Biology (Basel). 2019;8:37.

75. Langley MR, Yoon $\mathrm{H}$, Kim HN, et al. High fat diet consumption results in mitochondrial dysfunction, oxidative stress, and oligodendrocyte loss in the central nervous system. BBA Mol Basis Dis. 2020;1866:165630.

76. Tandon A, Singh SJ, Chaturvedi RK. Stem cells as potential targets of polyphenols in multiple sclerosis and Alzheimer's disease. Biomed Res Int. 2018;2018:1-30.

77. Vural G, Gümüşyayla Ş, Deniz O, et al. Relationship between thioldisulphide homeostasis and visual evoked potentials in patients with multiple sclerosis. Neurol Sci. 2018;40:385-391.

78. Ferrington DA, Fisher CR, Kowluru RA. Mitochondrial defects drive degenerative retinal diseases. Trends Mol Med. 2020;26:105-118.

79. Schmidlin CJ, Dodson MB, Madhavan L, et al. Redox regulation by NRF2 in aging and disease. Free Radic Biol Med. 2019;134:702-707.

80. Weissig V. Drug development for the therapy of mitochondrial diseases. Trends Mol Med. 2020;26:40-57.

81. Bahrami SA, Bakhtiari N. Ursolic acid regulates aging process through enhancing of metabolic sensor proteins level. Biomed Pharmacother. 2016;82:8-14.

82. Brunoni $A R$, Supasitthumrong $T$, Teixeira $A L$, et al. Differences in the immune-inflammatory profiles of unipolar and bipolar depression. J Affect Disord. 2020;262:8-15.

83. Buendia I, Michalska P, Navarro E, et al. Nrf2-ARE pathway: an emerging target against oxidative stress and neuroinflammation in neurodegenerative diseases. Pharmacol Ther. 2016;157:84-104.

84. Caprariello AV, Stys PK. Turned inside out: will myelin-protective therapies become the next-generation anti-inflammatories? DNA Cell Biol. 2019;38:219-222.

85. Cobley JN, Fiorello ML, Bailey DM. 13 reasons why the brain is susceptible to oxidative stress. Redox Biol. 2018;15:490-503.

86. Lejri I, Agapouda A, Grimm A, et al. Mitochondria- and oxidative stress targeting substances in cognitive decline-related disorders: from molecular mechanisms to clinical evidence. Oxid Med Cell Longev. 2019; 2019:9695412.

87. Waslo C, Bourdette D, Gray N, et al. Lipoic acid and other antioxidants as therapies for multiple sclerosis. Curr Treat Options Neurol. 2019;21:26.

88. Zeldich $E$, Chen $C-D$, Colvin TA, et al. The neuroprotective effect of Klotho is mediated via regulation of members of the redox system. J Biol Chem. 2014;289:24700-24715.

89. Chen X, Wang F, Gan J, et al. Myelin deficits caused by olig2 deficiency lead to cognitive dysfunction and increase vulnerability to social withdrawal in adult mice. Neurosci Bull. 2020 [Epub ahead of print]; DOI: 10.1007/s12264-019-00449-7

90. Reiche L, Küry P, Göttle P. Aberrant oligodendrogenesis in Down syndrome: shift in gliogenesis? Cells. 2019;8:1591.

91. Shimizu T, Osanai Y, Ikenaka K. Oligodendrocyte-neuron interactions: impact on myelination and brain function. Neurochem Res. 2018;43: 190-194.

92. Blacher E, Bashiardes $\mathrm{S}$, Shapiro $\mathrm{H}$, et al. Potential roles of gut microbiome and metabolites in modulating ALS in mice. Nature. 2019;572 474-480.

93. Belenguer P, Duarte JMN, Schuck PF, et al. Mitochondria and the brain: bioenergetics and beyond. Neurotox Res. 2019;36:219-238.

94. Cuadrado A, Rojo Al, Wells G, et al. Therapeutic targeting of the NRF2 and KEAP1 partnership in chronic diseases. Nat Rev Drug Discov. 2019; 18:295-317.

95. Morris G, Puri BK, Walder K, et al. The endoplasmic reticulum stress response in neuroprogressive diseases: emerging pathophysiological role and translational implications. Mol Neurobiol. 2018;55:8765-8787.
96. Smith EF, Shaw PJ, De Vos KJ. The role of mitochondria in amyotrophic lateral sclerosis. Neurosci Lett. 2019;710:132933.

97. Berridge MJ. Vitamin D cell signalling in health and disease. Biochem Biophys Res Commun. 2015;460:53-71.

98. de Cabo R, Mattson MP. Effects of intermittent fasting on health, aging, and disease. N Engl J Med. 2019;381:2541-2551.

99. Campisi J, Kapahi P, Lithgow GJ, et al. From discoveries in ageing research to therapeutics for healthy ageing. Nature. 2019;571:183-192.

100. Di Liegro CM, Schiera G, Proia P, et al. Physical activity and brain health. Genes. 2019;10:720.

101. Evans LW, Stratton MS, Ferguson BS. Dietary natural products as epigenetic modifiers in aging-associated inflammation and disease. Nat Prod Rep. 2020 [Epub ahead of print]; DOI: 10.1039/c9np00057g

102. Georgiou A, Lisacek-Kiosoglous A, Yiallouris A, et al. Klotho: the protein of faith. EC Neurol. 2017;7:189-223.

103. Huang $C, W u J$, Chen $D$, et al. Effects of sulforaphane in the central nervous system. Eur J Pharmacol. 2019;853:153-168.

104. Melchor GS, Khan T, Reger JF, et al. Remyelination pharmacotherapy investigations highlight diverse mechanisms underlying multiple sclerosis progression. ACS Pharmacol Transl Sci. 2019;2:372-386.

105. Rani L, Mondal AC. Emerging concepts of mitochondrial dysfunction in Parkinson's disease progression: pathogenic and therapeutic implications. Mitochondrion. 2020;50:25-34.

106. Rowin J. Integrative neuromuscular medicine: neuropathy and neuropathic pain: consider the alternatives. Muscle Nerve. 2019;60:124-136.

107. Suomalainen A, Battersby BJ. Mitochondrial diseases: the contribution of organelle stress responses to pathology. Nat Rev Mol Cell Biol. 2018;19: 77-92.

108. Watson K, Nasca C, Aasly L, et al. Insulin resistance, an unmasked culprit in depressive disorders: promises for interventions. Neuropharmacology. 2018;136:327-334.

109. Liu Y, Yan T, Chu JM-T, et al. The beneficial effects of physical exercise in the brain and related pathophysiological mechanisms in neurodegenerative diseases. Lab Invest. 2019;99:943-957.

110. Chu F, Shi M, Lang Y, et al. Gut microbiota in multiple sclerosis and experimental autoimmune encephalomyelitis: current applications and future perspectives. Mediators Inflamm. 2018;2018:8168717.

111. Faiq MA, Wollstein G, Schuman JS, et al. Cholinergic nervous system and glaucoma: from basic science to clinical applications. Prog Retin Eye Res. 2019;72:100767.

112. Faissner S, Plemel JR, Gold R, et al. Progressive multiple sclerosis: from pathophysiology to therapeutic strategies. Nat Rev Drug Discov. 2019; 18:905-922.

113. Mehrabani G, Aminian S, Mehrabani G, et al. Dietetic plans within the multiple sclerosis community: a review. Int J Nutr Sci. 2019;4:14-22.

114. Stadelmann C, Timmler S, Barrantes-Freer A, et al. Myelin in the central nervous system: structure, function, and pathology. Physiol Rev. 2019; 99:1381-1431.

115. Zeng Q, Gong J, Liu X, et al. Gut dysbiosis and lack of short chain fatty acids in a Chinese cohort of patients with multiple sclerosis. Neurochem Int. 2019;129:104468

116. Cserép C, Pósfai B, Orsolits B, et al. Microglia monitor and protect neuronal function via specialized somatic purinergic junctions. Science. 2020;367:528-537.

117. Prinz M, Jung S, Priller J. Microglia biology: one century of evolving concepts. Cell. 2019;179:292-311.

118. Wright-Jin EC, Gutmann DH. Microglia as dynamic cellular mediators of brain function. Trends Mol Med. 2019;25:967-979.

119. Divolis G, Stavropoulos A, Manioudaki M, et al. Activation of both transforming growth factor- $\beta$ and bone morphogenetic protein signalling pathways upon traumatic brain injury restrains pro-inflammatory and boosts tissue reparatory responses of reactive astrocytes and microglia. Brain Commun. 2019;1:fcz028.

120. Paschalis El, Lei F, Zhou C, et al. Permanent neuroglial remodeling of the retina following infiltration of CSF1R inhibition-resistant peripheral monocytes. Proc Natl Acad Sci U S A. 2018;115:E11359-E11368.

121. Paschalis El, Lei F, Zhou C, et al. Microglia regulate neuroglia remodeling in various ocular and retinal injuries. J Immunol. 2019;202:539-549.

122. Sierra A, Paolicelli RC, Kettenmann H. Cien años de microglía: milestones in a century of microglial research. Trends Neurosci. 2019:42:778-792.

123. Kim MJ, Kang JH, Theotokis $P$, et al. Can we design a Nogo receptordependent cellular therapy to target MS? Cells. 2019;8:E1. 
124. Lin W, Stone S. Unfolded protein response in myelin disorders. Neural Regen Res. 2020;15:636-645.

125. Shaimardanova AA, Solovyeva VV, Chulpanova DS, et al. Extracellular vesicles in the diagnosis and treatment of central nervous system diseases. Neural Regen Res. 2020;15:586-596.

126. Cassereau J, Chevrollier A, Codron $P$, et al. Oxidative stress contributes differentially to the pathophysiology of Charcot-Marie-Tooth disease type 2K. Exp Neurol. 2020;323:113069.

127. Wu X. Genome expression profiling predicts the molecular mechanism of peripheral myelination. Int J Mol Med. 2018;41:1500-1508.

128. Bergner CG, Meer $F$, Winkler A, et al. Microglia damage precedes major myelin breakdown in X-linked adrenoleukodystrophy and metachromatic leukodystrophy. Glia. 2019;67:1196-1209.

129. Creus-Muncunill J, Ehrlich ME. Cell-autonomous and non-cellautonomous pathogenic mechanisms in Huntington's disease: insights from in vitro and in vivo models. Neurotherapeutics. 2019;16:957-978.

130. Soloveva MV, Jamadar SD, Poudel G, et al. A critical review of brain and cognitive reserve in Huntington's disease. Neurosci Biobehav Rev. 2018; 88:155-169.

131. Duncan ID, Radcliff AB. Inherited and acquired disorders of myelin: the underlying myelin pathology. Exp Neurol. 2016;283:452-475.

132. Tricaud N, Gautier B, Hameren GV, et al. Schwann cell demyelination is triggered by a transient mitochondrial calcium release through Voltage Dependent Anion Channel 1. bioRxiv. 2019;2019:581157.

133. Lesch K-P. Editorial: can dysregulated myelination be linked to ADHD pathogenesis and persistence? J Child Psychol Psychiatry. 2019;60: 229-231.

134. Taylor MJ, Larsson H, Gillberg C, et al. Investigating the childhood symptom profile of community-based individuals diagnosed with attention-deficit/hyperactivity disorder as adults. J Child Psychol Psychiatry. 2019;60:259-266.

135. Kodama L, Guzman E, Etchegaray Jl, et al. Microglial microRNAs mediate sex-specific responses to tau pathology. Nat Neurosci. 2020;23: 167-171.

136. Bär L, Stournaras $C$, Lang F, et al. Regulation of fibroblast growth factor 23 (FGF 23) in health and disease. FEBS Lett. 2019;593:1879-1900.

137. Brown RB. Dysregulated phosphate metabolism, periodontal disease, and cancer: possible global health implications. Dent J (Basel). 2019;7: E18.

138. Bacchetta J, Bardet C, Prié D. Physiology of FGF23 and overview of genetic diseases associated with renal phosphate wasting. Metabolism. 2020;103S:153865.

139. Chen G, Liu Y, Goetz R, et al. $\alpha$-Klotho is a non-enzymatic molecular scaffold for FGF23 hormone signalling. Nature. 2018;553:461-466.

140. Jackson TC, Kochanek PM. A new vision for therapeutic hypothermia in the era of targeted temperature management: a speculative synthesis. Ther Hypothermia Temp Manag. 2019;9:13-47.

141. Kim J-M, Lee W-S, Kim J. Therapeutic strategy for atherosclerosis based on bone-vascular axis hypothesis. Pharmacol Ther. 2020;206:107436.

142. Klaus S, Ost M. Mitochondrial uncoupling and longevity - A role for mitokines? Exp Gerontol. 2020;130:110796.

143. Kuroda M, Muramatsu R, Maedera N, et al. Peripherally derived FGF2 promotes remyelination in the central nervous system. J Clin Invest. 2017;127:3496-3509.

144. Kuzina ES, Ung PM-U, Mohanty J, et al. Structures of ligand-occupied $\beta$-Klotho complexes reveal a molecular mechanism underlying endocrine FGF specificity and activity. Proc Natl Acad Sci U S A. 2019, 116:7819-7824.

145. Ornitz DM, Itoh N. The Fibroblast Growth Factor signaling pathway. Wiley Interdiscip Rev Dev Biol. 2015;4:215-266.

146. Ye L, Wang X, Cai C, et al. FGF21 promotes functional recovery after hypoxic-ischemic brain injury in neonatal rats by activating the PI3K/Akt signaling pathway via FGFR1/ $\beta$-klotho. Exp Neurol. 2019;317:34-50.

147. Abolghasemi $M$, Yousefi $T$, Maniati $M$, et al. The interplay of Klotho with signaling pathway and microRNAs in cancers. J Cell Biochem. 2019;120: 14306-14317.

148. Li X. The FGF metabolic axis. Front Med. 2019;13:511-530.

149. Faye PA, Poumeaud F, Miressi F, et al. Focus on 1,25-dihydroxyvitamin D3 in the peripheral nervous system. Front Neurosci. 2019;13:348.

150. Berridge MJ. Vitamin $D$, reactive oxygen species and calcium signalling in ageing and disease. Philos Trans R Soc Lond B Biol Sci. 2016;371: 20150434.
151. Berridge MJ. Vitamin D deficiency: infertility and neurodevelopmental diseases (attention deficit hyperactivity disorder, autism, and schizophrenia). Am J Physiol Cell Physiol. 2018;314:C135-C151.

152. Chen L, Yang R, Qiao W, et al. 1,25-Dihydroxyvitamin D exerts an antiaging role by activation of Nrf2-antioxidant signaling and inactivation of p16/p53-senescence signaling. Aging Cell. 2019;18:e12951.

153. Wimalawansa SJ. Vitamin D deficiency: effects on oxidative stress, epigenetics, gene regulation, and aging. Biology (Basel). 2019;8:E30.

154. Kaarniranta K, Pawlowska E, Szczepanska J, et al. Can vitamin D protect against age-related macular degeneration or slow its progression? Acta Biochim Pol. 2019;66:147-158,

155. Murdaca G, Tonacci A, Negrini S, et al. Emerging role of vitamin D in autoimmune diseases: an update on evidence and therapeutic implications. Autoimmun Rev. 2019;18:102350.

156. Guo Y, Zhuang X-D, Xian W-B, et al. Serum Klotho, vitamin D, and homocysteine in combination predict the outcomes of Chinese patients with multiple system atrophy. CNS Neurosci Ther. 2017;23:657-666.

157. Lang $F$, Ma K, Leibrock CB. $1,25(\mathrm{OH})_{2} \mathrm{D}_{3}$ in brain function and neuropsychiatric disease. Neurosignals. 2019;27:40-49.

158. Vlot MC, Boekel L, Kragt J, et al. Multiple sclerosis patients show lower bioavailable $25(\mathrm{OH}) \mathrm{D}$ and $1,25(\mathrm{OH})_{2} \mathrm{D}$, but no difference in ratio of 25(OH)D/24,25(OH) $)_{2} \mathrm{D}$ and FGF23 concentrations. Nutrients. 2019;11: E2774.

159. de la Vega Gallardo N, Dittmer M, Dombrowski Y, et al. Regenerating CNS myelin: emerging roles of regulatory T cells and CCN proteins. Neurochem Int. 2019;130:104349.

160. Filippi M, Bar-Or A, Piehl F, et al. Author Correction: multiple sclerosis. Nat Rev Dis Primers. 2018;4:49.

161. Patel $\mathrm{CH}$, Leone RD, Horton MR, et al. Targeting metabolism to regulate immune responses in autoimmunity and cancer. Nat Rev Drug Discov. 2019;18:669-688.

162. Rommer PS, Sellner J. Repurposing multiple sclerosis drugs: a review of studies in neurological and psychiatric conditions. Drug Discov Today. 2019;24:1398-1404

163. Saidu NEB, Kavian N, Leroy K, et al. Dimethyl fumarate, a two-edged drug: current status and future directions. Med Res Rev. 2019;39:19231952.

164. Vilariño-Güell C, Zimprich A, Martinelli-Boneschi $F$, et al. Exome sequencing in multiple sclerosis families identifies 12 candidate genes and nominates biological pathways for the genesis of disease. PLoS Genet. 2019;15:e1008180.

165. Yi W, Schlüter D, Wang X. Astrocytes in multiple sclerosis and experimental autoimmune encephalomyelitis: star-shaped cells illuminating the darkness of CNS autoimmunity. Brain Behav Immun. 2019;80:10-24

166. Duncan ID, Watters JJ. Remyelination and the gut-brain axis. Proc Nat Acad Sci U S A. 2019;116:24922-24924

167. Pahan S, Pahan K. Mode of action of aspirin in experimental autoimmune encephalomyelitis. DNA Cell Biol. 2019;38:593-596.

168. Wallin MT, Culpepper WJ, Nichols $E$, et al. Global, regional, and national burden of multiple sclerosis 1990-2016: a systematic analysis for the Global Burden of Disease Study 2016. Lancet Neurol. 2019;18:269-285.

169. Gholamzad M, Ebtekar M, Ardestani MS, et al. A comprehensive review on the treatment approaches of multiple sclerosis: currently and in the future. Inflamm Res. 2019;68:25-38.

170. Kaplon H, Reichert JM. Antibodies to watch in 2018. MAbs. 2018;10: 183-203.

171. Montalban X, Gold R, Thompson AJ, et al. ECTRIMS/EAN Guideline on the pharmacological treatment of people with multiple sclerosis. Mult Scler. 2018;24:96-120.

172. Rae-Grant A, Day GS, Marrie RA, et al. Practice guideline recommendations summary: disease-modifying therapies for adults with multiple sclerosis. Neurology. 2018;90:777-788.

173. Feustel AC, Macpherson A, Fergusson DA, et al. Risks and benefits of unapproved disease-modifying treatments for neurodegenerative disease. Neurology. 2020;94:e1-e14

174. Rezak M, Carvalho MD. Disease modification in neurodegenerative diseases. Not quite there yet. Neurology. 2020;94:12-13.

175. Hooijmans CR, Hlavica M, Schuler FAF, et al. Remyelination promoting therapies in multiple sclerosis animal models: a systematic review and meta-analysis. Sci Rep. 2019;9:822.

176. Kremer D, Göttle P, Flores-Rivera J, et al. Remyelination in multiple sclerosis: from concept to clinical trials. Curr Opin Neurol. 2019;32:378-384. 
177. Wooliscroft $L_{,}$Silbermann $E_{,}$Cameron $M$, et al. Approaches to remyelination therapies in multiple sclerosis. Curr Treat Options Neurol. 2019; 21:34.

178. Yu S, Liu M, Hu K. Natural products: potential therapeutic agents in multiple sclerosis. Int Immunopharmacol. 2019;67:87-97.

179. Kumar R, Harilal S, Gupta SV, et al. Exploring the new horizons of drug repurposing: a vital tool for turning hard work into smart work. Eur J Med Chem. 2019;182:111602.

180. Mucke H. An answerable challenge. EBR. July 2019: pages 14-17. https:// repo-trial.eu/wp-content/uploads/2019/07/Drug-Repurposing-forNeurodegeneration-Mucke-EBR-July-2019.pdf

181. Moos WH, Faller DV, Glavas IP, et al. Epigenetic treatment of dermatologic disorders. Drug Dev Res. 2019;80:702-713.

182. Polamreddy $P$, Gattu N. The drug repurposing landscape from 2012 to 2017: evolution, challenges, and possible solutions. Drug Discov Today. 2019;24:789-795.

183. Olauson $\mathrm{H}$, Mencke $\mathrm{R}$, Hillebrands $\mathrm{J}-\mathrm{L}$, et al. Tissue expression and source of circulating $\alpha$-Klotho. Bone. 2017;100:19-35.

184. Zhu L, Stein LR, Kim D, et al. Klotho controls the brain-immune system interface in the choroid plexus. Proc Natl Acad Sci U S A. 2018;115: E11388-E11396.

185. Dalton GD, Xie J, An S-W, et al. New insights into the mechanism of action of soluble klotho. Front Endocrinol. 2017;8:323.

186. Kawabata $\mathrm{C}$, Komaba $\mathrm{H}$, Ishida $\mathrm{H}$, et al. Changes in fibroblast growth factor 23 and soluble klotho levels after hemodialysis initiation. Kidney Med. 2020;2:59-67.

187. Lim K, Halim A, Lu T-S, et al. Klotho: a major shareholder in vascular aging enterprises. Int J Mol Sci. 2019;20:E4637.

188. Mazucanti $\mathrm{CH}$, Kawamoto EM, Mattson MP, et al. Activity-dependent neuronal Klotho enhances astrocytic aerobic glycolysis. J Cereb Blood Flow Metab. 2019:39:1544-1556.

189. Tai NC, Kim S-A, Ahn S-G. Soluble klotho regulates the function of salivary glands by activating KLF4 pathways. Aging (Albany NY). 2019;11: 8254-8269.

190. Hu Z-J, Wang X-C, Zhu L-C, et al. Circulating Klotho is linked to prognosis of acute intracerebral hemorrhage. Clin Chim Acta. 2019;497: $114-119$.

191. Ma X, Li H, Chen $\mathrm{Y}$, et al. The transcription factor MITF in RPE function and dysfunction. Prog Retin Eye Res. 2019;73:100766.

192. Alkozi HA, Franco R, Pintor JJ. Epigenetics in the eye: an overview of the most relevant ocular diseases. Front Genet. 2017;8:144.

193. Fan J, Lerner J, Wyatt MK, et al. The klotho-related protein KLPH (Ictl) has preferred expression in lens and is essential for expression of clic5 and normal lens suture formation. Exp Eye Res. 2018;169:111-121.

194. Reish NJ, Maltare A, Mckeown AS, et al. The age-regulating protein Klotho is vital to sustain retinal function. Invest Ophthalmol Vis Sci. 2013; 54:6675-6685.

195. Wong CW, Wong TY, et al. Kidney and eye diseases: common risk factors, etiological mechanisms, and pathways. Kidney Int. 2014;85: 1290-1302.

196. Yamamoto K, Sato K, Yukita M, et al. The neuroprotective effect of latanoprost acts via klotho-mediated suppression of calpain activation after optic nerve transection. J Neurochem. 2017;140:495508.

197. Oh HJ, Nam BY, Wu M, et al. Klotho plays a protective role against glomerular hypertrophy in a cell cycle-dependent manner in diabetic nephropathy. Am J Physiol Renal Physiol. 2018;315:F791-F805.

198. Oh HJ, Oh H, Nam BY, et al. The protective effect of klotho against contrast-associated acute kidney injury via the antioxidative effect. Am J Physiol Renal Physiol. 2019;317:F881-F889.

199. Ji B, Wei H, Ding $Y$, et al. Protective potential of klotho protein on diabetic retinopathy: evidence from clinical and in vitro studies. J Diabetes Invest. 2020;11:162-169.

200. Skowronska-Krawczyk D, Budin I. Aging membranes: unexplored functions for lipids in the lifespan of the central nervous system. Exp Gerontol. 2020;131:110817.

201. Matiello M, Juliano AF, Bowley M, et al. Case 21-2019: a 31-year-old woman with vision loss. N Engl J Med. 2019;381:164-172.

202. Waldman AT, Yeshokumar AK, Lavery A, et al. Validation of a symptombased questionnaire for pediatric CNS demyelinating diseases. J AAPOS. 2019;23:157.e1-157.e7.
203. Hashemian M, Ghasemi-Kasman M, Parsian H, et al. Fingolimod (FTY720) improves the functional recovery and myelin preservation of the optic pathway in focal demyelination model of rat optic chiasm. Brain Res Bull. 2019;153:109-121.

204. Manogaran P, Samardzija M, Schad AN, et al. Retinal pathology in experimental optic neuritis is characterized by retrograde degeneration and gliosis. Acta Neuropathol Commun. 2019;7:116.

205. Andhavarapu S, Mubariz F, Arvas M, et al. Interplay between ER stress and autophagy: a possible mechanism in multiple sclerosis pathology. Exp Mol Pathol. 2019;108:183-190.

206. Behrangi N, Fischbach F, Kipp M. Mechanism of siponimod: antiinflammatory and neuroprotective mode of action. Cells. 2019;8:24.

207. Gruchot J, Weyers V, Göttle P, et al. The molecular basis for remyelination failure in multiple sclerosis. Cells. 2019;8:825.

208. Moura RP, Sarmento B. Therapeutic approaches toward multiple sclerosis: where do we stand and where are we headed? Adv Ther. 2019;2: 1900070.

209. Nicaise AM, Wagstaff $L$, Willis CM, et al. Cellular senescence in progenitor cells contributes to diminished remyelination potential in progressive multiple sclerosis. Proc Natl Acad Sci U S A. 2019;116:90309039.

210. Peshes-Yeloz N, Ungar L, Wohl A, et al. Role of Klotho protein in tumor genesis, cancer progression, and prognosis in patients with high-grade glioma. World Neurosurg. 2019;130:e324-e332.

211. Robinson RR, Dietz AK, Maroof AM, et al. The role of glial-neuronal metabolic cooperation in modulating progression of multiple sclerosis and neuropathic pain. Immunotherapy. 2019;11:129-147.

212. Rao Z, Landry T, Li P, et al. Administration of alpha klotho reduces liver and adipose lipid accumulation in obese mice. Heliyon. 2019;5 e01494.

213. Abraham CR, Chen C, Cuny GD, et al. Small-molecule Klotho enhancers as novel treatment of neurodegeneration. Future Med Chem. 4:16711679.

214. Pérez-Hernández J, Zaldívar-Machorro VJ, Villanueva-Porras D, et al. A potential alternative against neurodegenerative diseases: phytodrugs. Oxid Med Cell Longev. 2016;2016:8378613.

215. Liao H-K, Hatanaka F, Araoka T, et al. In vivo target gene activation via CRISPR/Cas9-mediated trans-epigenetic modulation. Cell. 2017;171: 1495-1507.

216. Lin $\mathrm{W}, \mathrm{Li} \mathrm{Y}, \mathrm{Chen} \mathrm{F}$, et al. Klotho preservation via histone deacetylase inhibition attenuates chronic kidney disease-associated bone injury in mice. Sci Rep. 2017;7:46195.

217. Lu G, Zhang M, Wang J, et al. Epigenetic regulation of myelination in health and disease. Eur J Neurosci 2019;49:1371-1387.

218. Tomaselli D, Lucidi A, Rotili D, et al. Epigenetic polypharmacology: a new frontier for epi-drug discovery. Med Res Rev. 2020;40:190-244.

219. VandenBosch LS, Reh TA. Epigenetics in neuronal regeneration. Semin Cell Dev Biol. 2020;97:63-73.

220. Davidsohn N, Pezone $M$, Vernet $A$, et al. A single combination gene therapy treats multiple age-related diseases. Proc Natl Acad Sci U S A. 2019;116:23505-23511.

221. Vaiserman A, Falco ED, Koliada A, et al. Anti-ageing gene therapy: not so far away? Ageing Res Rev. 2019;56:100977.

222. Xu L, Liu T, Liu $L$, et al. Global variation in prevalence and incidence of amyotrophic lateral sclerosis: a systematic review and metaanalysis. J Neurol. 2020 [Epub ahead of print]; DOI: 10.1007/s00415-01909652-y

223. Volonté C, Apolloni S, Sabatelli M. Histamine beyond its effects on allergy: potential therapeutic benefits for the treatment of Amyotrophic Lateral Sclerosis (ALS). Pharmacol Ther. 2019;202:120-131.

224. Brown RH, Al-Chalabi A. Amyotrophic lateral sclerosis. N Engl J Med. 2017;377:162-172.

225. Galvin M, Gaffney R, Corr B, et al. From first symptoms to diagnosis of amyotrophic lateral sclerosis: perspectives of an Irish informal caregiver cohort-a thematic analysis. BMJ Open. 2017;7:e014985

226. Paganoni $S$, Macklin EA, Lee A, et al. Diagnostic timelines and delays in diagnosing amyotrophic lateral sclerosis (ALS). Amyotroph Lateral Scler Frontotemporal Degener. 2014;15:453-456. doi: 10.3109/21678421.2014.903974

227. Zwicker J, Qureshi D, Talarico R, et al. Dying of amyotrophic latera sclerosis. Neurology. 2019;93:e2083-e2093. 
228. Swindell WR, Kruse CPS, List EO, et al. ALS blood expression profiling identifies new biomarkers, patient subgroups, and evidence for neutrophilia and hypoxia. J Transl Med. 2019;17:170.

229. van den Berg LH, Sorenson E, Gronseth G, et al. Revised Airlie House consensus guidelines for design and implementation of ALS clinical trials. Neurology. 2019;92:e1610-e1623.

230. Bedlack R, Wicks P, Vaughan T, et al. Lunasin does not slow ALS progression: results of an open-label, single-center, hybrid-virtual 12-month trial. Amyotroph Lateral Scler Frontotemporal Degener. 2019;20:285-293.

231. Wheeler RJ, Lee HO, Poser I, et al. Small molecules for modulating protein driven liquid-liquid phase separation in treating neurodegenerative disease. bioRxiv. 2019;2019:721001.

232. Dervishi I, Ozdinler PH. Incorporating upper motor neuron health in ALS drug discovery. Drug Discov Today. 2018;23:696-703.

233. Fralick M, Sacks CA, Kesselheim AS. Assessment of use of combined dextromethorphan and quinidine in patients with dementia or Parkinson disease after US Food and Drug Administration approval for pseudobulbar affect. JAMA Intern Med. 2019;179:224-230.

234. Brown DG, Shorter J, Wobst HJ. Emerging small-molecule therapeutic approaches for amyotrophic lateral sclerosis and frontotemporal dementia. Bioorg Med Chem Lett. 2020;30:126942.

235. Brown DG, Wobst HJ. Opportunities and challenges in phenotypic screening for neurodegenerative disease research. J Med Chem. 2020; 63:1823-1840.

236. Granucci EJ, Griciuc A, Mueller KA, et al. Cromolyn sodium delays disease onset and is neuroprotective in the SOD1G93A mouse model of amyotrophic lateral sclerosis. Sci Rep. 2019;9:17728.
Cite this article as: Moos WH, Faller DV, Glavas IP, Harpp DN, Kanara I, Mavrakis AN, Pernokas J, Pernokas M, Pinkert CA, Powers WR, Sampani K, Steliou K, Vavvas DG, Zamboni RJ, Kodukula K, Chen X (2020) Klotho pathways, myelination disorders, neurodegenerative diseases, and epigenetic drugs, BioResearch Open Access 9:1, 94-105, DOI: 10.1089/biores.2020.0004.

\author{
Abbreviations Used \\ $A D=$ Alzheimer's disease \\ ALS $=$ amyotrophic lateral sclerosis \\ CNS $=$ central nervous system \\ $\mathrm{DMT}=$ disease modifying therapy \\ FDA $=$ Food and Drug Administration \\ FGF $=$ fibroblast growth factor \\ LOAD = late-onset Alzheimer's disease \\ $\mathrm{MS}=$ multiple sclerosis \\ OS $=$ oxidative stress \\ $\mathrm{PD}=$ Parkinson's disease \\ PNS $=$ peripheral nervous system \\ $\mathrm{ROS}=$ reactive oxygen species
}

\section{Publish in BioResearch Open Access}

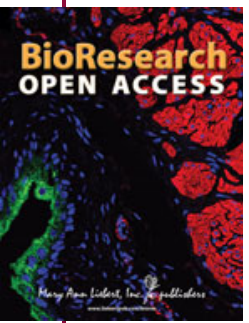

- Broad coverage of biomedical research

- Immediate, unrestricted online access

- Rigorous peer review

- Compliance with open access mandates

- Authors retain copyright

- Highly indexed

- Targeted email marketing

liebertpub.com/biores 